\title{
Seeking Substantiality: Evaluation of Public Attitudes toward Resilient Wastewater Reuse Management
}

\author{
Amin Daghighi, ${ }^{1}$ Ali Nahvi, ${ }^{2}$ Sara Nazif ${ }^{3}$ and Ungtae Kim $^{4}$ \\ ${ }^{1}$ Iowa State University, Ames, Iowa; ${ }^{2}$ SRF Consulting Engineering, Minneapolis, Minnesota; ${ }^{3}$ University of Tehran, Tehran, Iran; ${ }^{4}$ Cleveland State \\ University, Cleveland, Ohio.
}

\begin{abstract}
Because of Iran's limited water resources, maximum usage of available water resources is a high priority. In this case study of Tehran, Iran, academic and industrial applications of the strengths, weaknesses, opportunities and threats (SWOT) approach provide an analysis of the main challenges of wastewater reuse. One possible solution for dealing with water crises is to reuse water in different consumption areas. An important step in this regard is to evaluate the public attitude toward different usages of recycled water, and to increase public participation in this process. In addition, questionnaires offer quantitative analysis of people's preferences with respect to wastewater reuse. The results suggest that the Tehran water department should consider defensive approaches to developing public participation in wastewater reuse. The main underlying reasons people are in favour of wastewater reuse are the provision of environmental protection from contamination caused by wastewater and irrigating farmlands of non-food products.
\end{abstract}

\section{Introduction}

Many countries around the world currently suffer from a lack of available water resources to supply their various water demands. Rapid increases in population and uncertainty with respect to water resources have resulted in severe water shortages around the world (Daghighi 2017) which are likely to intensify in the future. In recent decades, reuse of wastewater has been considered as a new source of water in some countries. Moreover, it is obvious that lack of proper waste water management provokes excessive cost for the environment and for humans; however, a plausible study on the negative environmental impacts of deicing salt showed that due to difficulties in assigning a monetary value to environmental impacts, it is very difficult to calculate the overall cost (Habibzadeh-Bigdarvish et al. 2019). In the United Kingdom, 10\% of the water used in Essex (population 1.5 million) has been recycled, while in Singapore, $1 \%$ of the drinking water in 2007 was provided by the NEWater scheme, which produces high quality reclaimed water produced from treated used water that is further purified using advanced membrane technologies and ultra-violet disinfection, making it ultra-clean and safe to drink. This quantity increased to $2.5 \%$ by 2012 (Queensland Water Commission 2007).

Israel is known for its long and successful agricultural water reuse. A survey was conducted in Israel in 2006 to determine public opinion on various water treatment and reuse options.
Generally speaking, the survey responses showed considerable support for the notion of wastewater reuse schemes. To be more specific, options that were defined as medium contact (e.g. private gardening or car washing) received considerable support from public opinion. In addition, according to the analysis conducted in the study by Friedler et al. (2006), there was no correlation between the demographics of the interviewees and the level of support they showed for the use of medium contact reused water.

Many studies have been conducted in the United States to gain understanding of public attitudes towards utilizing reused water for many varieties of day to day activities (Angelakis and Gikas 2014; Dishman 1989; Honeycutt 2015). The results of these studies showed that there have been some significant barriers to the use of direct portable water reuse due to health concerns and public acceptance.

Successful reuse of wastewater greatly depends on economic and environmental issues (Haghiri et al. 2018; Gheytaspour and Habibzadeh-Bigdarvish 2018; Ketabchy 2018) together with public agreement, awareness and support. Gaining public support may be one of the most serious problems that a project will face. The main concerns regarding public participation are people's prejudiced beliefs, fears, unpredictable behaviours, lack of knowledge and education, and doubts about such a system being healthy, reliable and secure (Chen et al. 2015; Nahvi et al. 2018). The risk of failure in the development of wastewater

Daghighi, Amin, Ali Nahvi, Sara Nazif and Ungtae Kim. 2020. "Seeking Substantiality: Evaluation of Public Attitudes toward Resilient Wastewater Reuse Management." Journal of Water Management Modeling 28:C470. doi: 10.14796/JWMM.C470.

(c) CHI 2020. www.chijournal.org ISSN 2292-6062. 
reuse facilities without public participation could be high. Thus engineers and social scientists must work together in wastewater reuse projects, with engineers working on technical issues while social scientists identify why people are prejudiced against the reuse of water resources, provide suggestions about how to deal with this problem, and to improve awareness so that people accept the idea of wastewater reuse (Wu et al. 2009).

Regional surveys represent a way to provide information about people's beliefs about wastewater reuse. While the use of such surveys might be somewhat problematic for various reasons, such as adequate response options or rating level inconsistency, they have produced useful results regarding people's behaviour and beliefs about water resource management and treatment projects, such as wastewater reuse, in countries such as the United States, Australia, and some countries in Western Europe (McGovern and Bastian 2009; Hurlimann 2007; Bixio et al. 2006). In other regions of the world, less information of this type is available, making it difficult to make appropriate decisions about how to develop wastewater reuse projects (Baumann et al. 1974). The application of decision-making methods such as fuzzy decision-making can be very beneficial (Homaei et al. 2020), but due to the lack of nation-wide data, we used a regional survey to gather information about people's attitudes and concerns toward wastewater reuse, and the type of applications they prefer.

Published surveys about people's attitudes toward wastewater reuse can be divided into three categories (Friedler 2008). The first includes surveys that study people's general attitudes towards the reuse of water and ask them to answer wide ranging questions that are not necessarily about a specific impendent issue. The second category consists of studies of people's attitudes toward reuse projects in the near future, while the third group of studies evaluates people's attitudes toward existing wastewater reuse projects (Bruvold et al. 1981).

From an examination of available literature on public attitudes toward wastewater reuse (Bruvold and Ward 1972; Bruvold 1972; Sims and Baumann 1974; Po et al. 2003; Coomes et al. 2010; Wirth 2010; McKenzie 2004; Roman et al. 2007; World Health Organization 2006; Scott et al., 2000), we concluded that people do not have serious problems with the use of reused wastewater with which they would have little personal contact. However, people are unwilling to reuse water when it involves significant personal contact with the water, such as for drinking or bathing babies.

Such considerations underlie the schemes currently followed in many countries regarding wastewater reuse. For example, in Australia the reuse of water for non-drinking applications in agriculture and horticulture and household usage such as toilet flushing is accepted; however, for drinking there is zero social acceptance and it remains a more controversial issue (Po et al. 2003). Crook (2003) states that in the United States people generally favour non-drinking usage, while support for use as drinking water faces problems. Initial concerns are related to costs and public health protection, so people do enjoy financial gains from wastewater reuse that involves minimal personal contact.
Public disagreement with the idea of drinking recycled water has prevented many water recycling projects from being implemented around the world. In the United States, residents of San Diego and Tampa campaigned against wastewater reuse in the mid-1990s, mainly because there could be a stratification between people who can afford bottled water for drinking and those who cannot, and that poor districts would use sewage from rich districts as drinking water (Hartley 2006). In 2006, a similar community discussion took place in Australia about a local government plan for the reuse of water in the inner regional South East Queensland (SEQ) community of Toowoomba. In that case residents had inadequate knowledge about the process of wastewater treatment, and they refused to agree to the water recycling plan for high contact applications in a referendum (Miller et al. 2007).

A major aspect of past surveys was a focus on asking people about their willingness to use recycled wastewater, but a small number of surveys focused on identifying personal characteristics associated with high or low levels of willingness to use recycled wastewater. The key survey features included knowledge, information, previous experience in using recycled wastewater, and willingness to accept the risk. For example, Po et al. (2005) tested the general population's acceptance of indirect use of wastewater with results showing positive attitudes toward indirect reuse. These results were influenced by factors that included subjective normal behaviours, emotions, trust in authorities, risk-taking acceptance (negative), a sense of obligation to support the environment, and knowledge of control over the source of their drinking water.

Dolnicar et al. (2010) focused on a wide range of factors, both socio-demographic and psychographic, that affect wastewater reuse. They recognized that there has been little research about the general conditions of society, the effect of various cultural, social and economic parameters on people's perception, and the capability of public and private offices to recycle the used water. Since their report, there has still been little attention given to social parameters and their influence on a society's perception with respect to this issue.

The aim of this study is to investigate public attitudes toward wastewater reuse in Tehran, the capital of Iran, as well as preferred usages for recycled water. Because of significant limitations to water resources in the area studied and recent severe droughts, it seems that usage of recycled water could be necessary, so evaluation of the public attitude is an important issue with respect to successful development of wastewater reuse facilities. Two groups of residents, including experts and non-experts from the given population, were included in two separate surveys. The aim of the first survey was to evaluate the current status of wastewater reuse, and only experts were included. SWOT was used to analyze the results. The aim of the second survey, with heterogeneous social groups of participants, was to determine which types of recycled wastewater usage are preferred by people. 


\section{Materials and Methods}

\subsection{SWOT Analysis}

A questionnaire was developed to investigate current attitudes toward wastewater reuse and 52 experts were asked to respond. Parameters and factors effective in using the recycled wastewater were identified and were included in the questionnaire, which contained twenty-four questions related to current threats and opportunities. The experts were asked to rate the importance of each issue as high, moderate or low. Experts included professors and people with $>15$ y experience in this field.

SWOT was used in this research to analyze the results of the surveys for making decisions about the development of appropriate approaches toward developing wastewater reuse. The factors considered were categorized into four groups: strengths $(S)$, weaknesses $(\mathrm{W})$, opportunities $(\mathrm{O})$ and threats $(\mathrm{T})$. Internal factors affecting wastewater reuse included weaknesses and strengths, while external factors included opportunities and threats (Hill and Westbrook 1997).

In the next step, the weights and values of the factors were determined. The weights assigned to internal and external factors reflected their importance and their effects on decision making with respect to wastewater reuse. The value (score) of each factor shows its situation within the three states being considered, 1 (favourable), 2 (medium) or 3 (weak). The weighted scores of factors were obtained by multiplying the weights by their own average score. Since a considerable number of people participated in this survey, those questionnaires with results a distance more than one standard deviation away from the mean were omitted from the analysis. This decision was based on an assumed normal distribution of the results, and results between \pm 1 standard deviation covered about $95 \%$ of the participants that logically should be considered for strategy development. The remaining questionnaires were averaged to obtain the final values for the different factors.

A SWOT diagram was formed reflecting the four blocks $\mathrm{O}, \mathrm{S}, \mathrm{T}$ and $\mathrm{W}$. The intersection points of the accumulated results were found. The final positions, offensive (SO), competitive (ST), conservative (WO) and defensive (WT), were combined strategies to find a path for decreasing the weaknesses and the threats and converting them to strengths and opportunities. For this purpose, the SWOT inverse matrix that includes the weakness and strength points, the opportunities and threats, along with the SO, ST, WO and WT strategies, was used (Table 1). When this matrix is formed, a path from the area including weakness and threat to the area of strength and opportunity should be taken to prepare a proper strategy.

Table 1 SWOT matrix for preparing the strategy.

\begin{tabular}{l|cl}
\hline Internal Factors & Strong Points (S) & Weak Points (W) \\
\hline External Factors & SO Strategies & WO Strategies \\
Opportunities (0) & ST Strategies & WT Strategies \\
\hline
\end{tabular}

Another survey submitted to the public asked about types of recycled water usage. Those participating in this part of the survey were asked to prioritize the different groups of usage types, and the results are discussed in the following sections.

\subsection{Study Area and Data Collection}

Tehran, the capital of Iran, was selected as the study area of this paper. Tehran is the largest city in Iran with a population $\sim 8$ million in the urban area and $\sim 12$ million in the metropolitan area (Population and Household Census 2011). During the last 45 years the per capita renewable water resources of Tehran have decreased from $5500 \mathrm{~m}^{3} / \mathrm{y}$ to $1750 \mathrm{~m}^{3} / \mathrm{y}$ and this trend is expected to continue, declining more sharply in the next $15 \mathrm{y}$ to $<1000 \mathrm{~m}^{3} / \mathrm{y}$. In the near future, according to United Nations criteria, Tehran will face a serious water crisis.

Approximately $70 \%$ of the water demand in Tehran is supplied from three reservoirs in Lar Karaj and Latyan and the remaining 30\% is obtained from Tehran's ground water. Two other reservoirs, Taleghan and Mamloo, have also recently been used as water sources. Research in Tehran and its surrounding areas shows that further increase in surface water resources is impossible and most wells are also at risk of contamination (Tabesh and Dini 2009).

The total annual water demand of Tehran has exceeded 1 billion $\mathrm{m}^{3}$ in recent years. Developing a Tehran wastewater collection system would represent a potential resource of $\sim 800$ million $\mathrm{m}^{3} / \mathrm{y}$. Currently, $\sim 54$ million $\mathrm{m}^{3} / \mathrm{y}$ wastewater is collected and recycled. Because of water resource limitations, as well as development in urban areas and a growing population and climate change (decreased precipitation and increased temperatures) that threaten water resources, recycled wasted water could be a valuable resource for satisfying different types of water demand.

Although a sewage collection and treatment system was initiated in 2016, which will cover 15000 ha of the city, Tehran lacks municipal sewage facilities. Eventually, $>60 \%$ wastewater in the city penetrates the ground due to the lack of a sewage system (Ardalan and Hadi 2019).

However, before developing wastewater reuse facilities in this region, it is necessary to evaluate public attitudes towards this decision and provide a means for public participation in the process. A more effective public education program could be developed. For this purpose, a field survey was conducted and a random population was asked to respond to it. The survey was administered through interviews, and a total of 350 people, 200 males (57\%) and 150 females (43\%) responded, presenting positive or negative reactions to 10 situations described in 10 questions related to reusing recycled wastewater for different purposes. The main statistics and characteristics of the participating population are given in Table 2. The options shown in Table 3 were grouped into low, medium and high contact reuse options. People who had studied at the university level, or had worked within a field related to wastewater reuse, were considered as educated, as given in Table 2. 
Table 2 Information on participated population in completed questionnaires.

\begin{tabular}{lccc}
\hline Major group of people & Minor group of people & Population & Percentage \\
\hline All people & - & 350 & $100 \%$ \\
Familiarity & Unfamiliar & 233 & $67 \%$ \\
\multirow{3}{*}{ Gender } & Familiar & 117 & $33 \%$ \\
& Male & 200 & $57 \%$ \\
Age & Female & 150 & $43 \%$ \\
& Under 18 & 73 & $21 \%$ \\
& Age 18 to 30 & 138 & $39 \%$ \\
Education & Age 31 to 50 & 110 & $31 \%$ \\
& Age 51 to 70 & 25 & $7 \%$ \\
& Over than 70 & 4 & $2 \%$ \\
& Professor & 46 & $13 \%$ \\
Income & Graduated & 162 & $46 \%$ \\
& Literate & 129 & $37 \%$ \\
& Illiterate & 13 & $4 \%$ \\
& Upper class & 56 & $16 \%$ \\
\hline
\end{tabular}

Table 3 Wastewater reuse options with average scores from all respondents.

\begin{tabular}{clc}
\hline Wastewater category & \multicolumn{1}{c}{ Wastewater option } & $\begin{array}{c}\text { Acceptance } \\
\text { average score }\end{array}$ \\
\hline High contact & Canned foods and nutrition & $12.8 \%$ \\
& Public and private pools & $29.71 \%$ \\
& Washing machine and dishwashers & $40.73 \%$ \\
Medium contact & Irrigating vegetable and fruit gardens & $51.19 \%$ \\
& Water used to flush toilets & $85.01 \%$ \\
& Irrigating home gardens and urban green landscapes & $86.78 \%$ \\
& Water used by car washes & $90.24 \%$ \\
& Water in artificial lakes for recreation and boating & $93.51 \%$ \\
& Water used for fire extinguishers, nonfood and hygiene & $97.15 \%$ \\
& industries & \\
& Water used on irrigation for non-food products & $100 \%$ \\
\hline
\end{tabular}

People educated in the field of water resources, environmental science, or with work experiences in the field were considered Familiar and the rest were considered Unfamiliar. The Literate group was limited not only to primary or high school education level, but also includes undergraduates. The Professor group includes all Assistant, Associate and Full Professors. All those surveyed were divided, based on income, into three social classes: upper class, middle and working class, and lower class. The upper class income was $>\$ 40000 / y$, the lower class income was $<\$ 4000 / y$, and the middle and working class income was between these two values (Statistical Center of Iran 2013).

\section{Results and Discussion}

Table 3 shows the average value for the acceptance rate among all the categories. As shown in Table 3 all the partici- pants in the survey agreed with the use of treated water in nonfood and hygiene industries. The public attitude towards the use of reused water for artificial lakes, gardening, and flush toilets was very positive. This indicates that the participants were not sensitive about using reused water for low and medium contact applications. But as shown in the table below, for high contact situations, participants were not quite as optimistic regarding use of the treated water. This might be relate to the sensitivity of the public regarding the quality of the treated water and to health concerns that might be associated with reused water.

\subsection{Appropriate strategies for wastewater reuse based on expert comments}

The main internal and external factors that were recognized based on expert judgment with respect to wastewater reuse in the Tehran metropolitan area are given in Tables 4 and 5. A collection of the 16 factors with the highest scores was selected for further analysis in such a way that four factors in each block were identified. To make the results comparable the scores of these factors were normalized (Table 6).

The final average value of internal factors was 1.582. The most important strengths of the system were stated as first "the availability of monitoring structures for observing the quality of the recycled effluent online and preventing the low quality flow to enter the distribution system" and second "the availability and operation of the urban waste collection system." The main weaknesses of the system were "the availability of adequate processing plants and proper technology for refining the effluent" and "the availability of proper technology for refining the urban effluent according to the standards." The sum of the weighted scores for external factors was 1.821, as shown in Table 6. The opportunities that received the highest weighted scores based on expert judgments were "savings in water usage" and "helping to preserve the environment by refining the effluents and not discharging them into nature." The highest weighted scores in the threats were given to "the danger to personal and family health due to misuse of the refined effluent" and "creating problems for sensitive age groups (children and the elderly)."

By drawing the inner-outer matrix using the results of the SWOT analysis and referring to the combined strategies of SO, ST, WO and WT, appropriate strategies (from Table 1) can be specified. Figure 1 shows the results of the analysis; it can be seen that the intersection point of this system is in the WT sector, indicating that development of the wastewater reuse system has some weak points to which attention must be given and improvements sought. System threats have more weight than opportunities, but this is not due to any lack of opportunities. Thus the selected strategy based on SWOT analysis is the establishment of a defen- 
Table 4 Giving weights to the internal factors by experts.

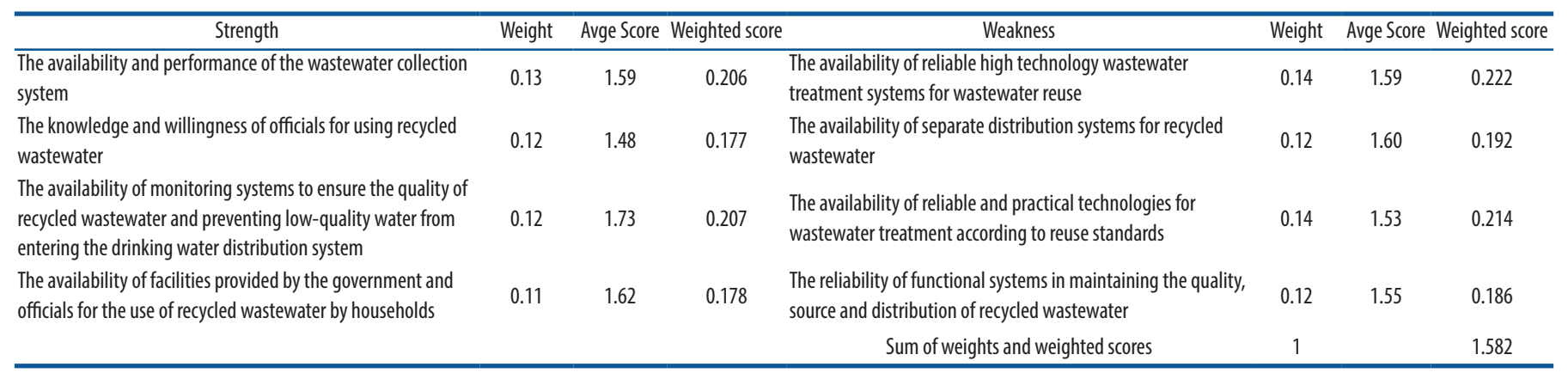

Table 5 Giving weights to the external factors by the experts' comments.

\begin{tabular}{|c|c|c|c|c|c|c|c|}
\hline Opportunity & Weight & Avge Score & Weighted score & Threat & Weight & Avge Score & Weighted score \\
\hline $\begin{array}{l}\text { The cost of recycled wastewater in comparison with the cost of } \\
\text { drinking water }\end{array}$ & 0.058 & 1.64 & 0.0951 & $\begin{array}{l}\text { The possibility of treated wastewater leaking into the drinking } \\
\text { water distribution system }\end{array}$ & 0.059 & 1.63 & 0.0961 \\
\hline Providing opportunities for investment in different areas of the & & & & The possibility of drainage of specific wastewaters, like & & & \\
\hline $\begin{array}{l}\text { country to develop or improve the water supply systems ability } \\
\text { to save water }\end{array}$ & 0.058 & 1.62 & 0.0939 & $\begin{array}{l}\text { hospitals and special industries, resulting in lower quality of } \\
\text { treated urban wastewater }\end{array}$ & 0.060 & 1.67 & 0.100 \\
\hline Savings in household income & 0.061 & 1.89 & 0.115 & $\begin{array}{l}\text { The discharge of urban wastewater to surface water resources } \\
\text { and preserving their quality }\end{array}$ & 0.065 & 1.78 & 0.116 \\
\hline $\begin{array}{l}\text { Healthier agricultural products through irrigation by treated } \\
\text { wastewater }\end{array}$ & 0.064 & 1.78 & 0.114 & $\begin{array}{l}\text { The discharge of urban wastewater to groundwater resources } \\
\text { and preserving their quality }\end{array}$ & 0.067 & 1.68 & 0.113 \\
\hline $\begin{array}{l}\text { Less chemical fertilizers applied because of nutrients available } \\
\text { in reused wastewater }\end{array}$ & 0.058 & 1.88 & 0.109 & $\begin{array}{l}\text { The hygiene and health problems due to misusing recycled } \\
\text { water }\end{array}$ & 0.076 & 1.70 & 0.129 \\
\hline Prevention of water resources from quality degradation & 0.067 & 1.75 & 0.117 & $\begin{array}{l}\text { Increasing family and social medical costs due to the unknown } \\
\text { effects of using recycled wastewater }\end{array}$ & 0.061 & 1.69 & 0.103 \\
\hline Protection of high quality water resources & 0.066 & 2.19 & 0.144 & $\begin{array}{l}\text { Creating problems for vulnerable parts of society (children and } \\
\text { the elderly) }\end{array}$ & 0.065 & 1.84 & 0.120 \\
\hline \multirow[t]{2}{*}{$\begin{array}{l}\text { Providing opportunities for industrial development in areas } \\
\text { with limited water resources }\end{array}$} & 0.060 & 1.82 & 0.109 & Permanent and reliable accessibility to recycled wastewater & 0.055 & 1.85 & 0.102 \\
\hline & & & & Sum of weights and weighted scores & 1 & & 1.776 \\
\hline
\end{tabular}

Table 6 The result of analysis on short list of most important factors selected for SWOT analysis.

\begin{tabular}{|c|c|c|c|c|c|c|c|}
\hline Internal Factors & Weight & Avge Score & Weighted score & External Factors & Weight & Avge Score & Weighted score \\
\hline Strengths & & & & \multicolumn{4}{|l|}{ Opportunities } \\
\hline $\begin{array}{l}\text { The availability of monitoring structures for observing the } \\
\text { quality of recycled effluent online and preventing low quality } \\
\text { flow from entering the distribution system }\end{array}$ & 0.12 & 1.73 & 0.207 & $\begin{array}{l}\text { Helping to preserve the environment by refining the effluent } \\
\text { and not discharging it into nature }\end{array}$ & 0.13 & 1.75 & 0.227 \\
\hline $\begin{array}{l}\text { The availability and proper operation of the urban waste } \\
\text { collecting system }\end{array}$ & 0.13 & 1.59 & 0.206 & Savings in water usage & 0.12 & 2.19 & 0.262 \\
\hline $\begin{array}{l}\text { The availability of facilities provided by the government and } \\
\text { officials for the use of the recycled effluent by families }\end{array}$ & 0.11 & 1.62 & 0.178 & Savings in family expenses & 0.12 & 1.89 & 0.227 \\
\hline $\begin{array}{l}\text { The knowledge and willingness of officials in using the } \\
\text { recycled effluent }\end{array}$ & 0.12 & 1.48 & 0.177 & $\begin{array}{l}\text { Increase in the level of hygiene in farm products and gardens } \\
\text { through irrigation by the refined effluent water }\end{array}$ & 0.12 & 1.78 & 0.214 \\
\hline Weaknesses & & & & \multicolumn{4}{|l|}{ Threats } \\
\hline $\begin{array}{l}\text { The availability of adequate refineries and proper technology } \\
\text { for the refinement of effluent }\end{array}$ & 0.14 & 1.59 & 0.222 & $\begin{array}{l}\text { The danger to the personal and family hygiene from misuse of } \\
\text { the refined effluent }\end{array}$ & 0.14 & 1.70 & 0.238 \\
\hline $\begin{array}{l}\text { The availability of proper technology for the refinement of } \\
\text { urban effluent according to usage standards }\end{array}$ & 0.14 & 1.53 & 0.214 & $\begin{array}{l}\text { Creating problems for sensitive age groups (children and the } \\
\text { elderly) }\end{array}$ & 0.12 & 1.84 & 0.221 \\
\hline $\begin{array}{l}\text { The availability of recycled effluent distribution infrastructures, } \\
\text { as separated from the drinking water }\end{array}$ & 0.12 & 1.60 & 0.192 & $\begin{array}{l}\text { The discharge of urban wastewater to surface water resources } \\
\text { (rivers) and preserving their quality }\end{array}$ & 0.12 & 1.78 & 0.214 \\
\hline \multirow[t]{2}{*}{$\begin{array}{l}\text { The reliability of operating systems in meeting standards } \\
\text { and the principles of supply and distribution of the recycled } \\
\text { drainage water }\end{array}$} & 0.12 & 1.55 & 0.186 & $\begin{array}{l}\text { The discharge of urban wastewater to underground water } \\
\text { resources and preserving their quality }\end{array}$ & 0.13 & 1.68 & 0.218 \\
\hline & & & & Sum of weights and weighted scores & 1 & & 1.776 \\
\hline
\end{tabular}


sive system. The main steps for advancing this strategy are:

1. Public education about the procedures for using recycled wastewater;

2. Informing the public about the quality of the recycled water and the availability of adequate and reliable technology and facilities in the country for providing high quality recycled water;

3. Making the public familiar with the benefits of using recycled water especially in dealing with water shortages and droughts; and

4. Changing drinking water tariffs to make it more closely reflect the real cost and informing people about the high value of water resources and the necessity for their preservation.
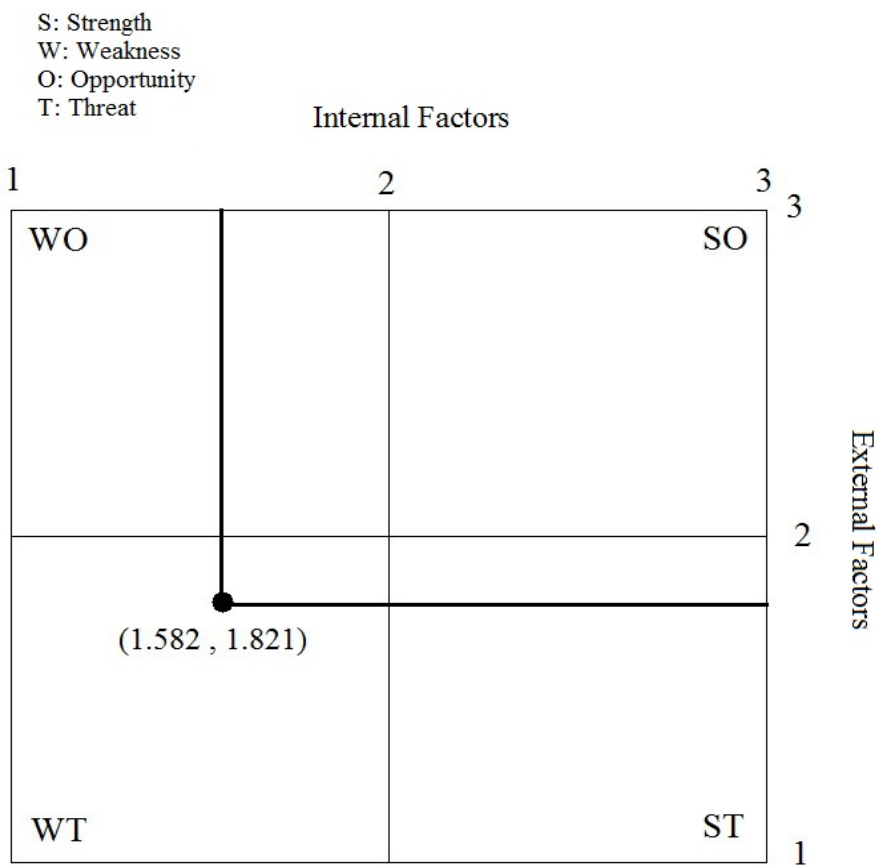

Figure 1 The inner-outer matrix obtained from the SWOT analysis based on expert judgments.

\subsection{Priorities in recycled water usage based on public ideas}

In the second survey, in which a variety of residents participated, they were first asked about reasons that would persuade them to accept wastewater reuse. The main reasons included in the questionnaire were "decreasing the cost of household water consumption," "preserving the quality of the environment," "savings in water use" and "increasing the health of society." About $36.54 \%$ of participants indicated "preserving the quality of the environment" as their main reason for using recycled water. "Savings in the usage of water" ranked second with $20.72 \%$ and "decreasing the household water consumption cost" was third with $9.09 \%$, as shown in Figure 2. Table 3 shows the average score given by all participants to each of the wastewater reuse alternatives in the survey. The results show that wastewater reuse is mostly accepted for low-contact purposes, emphasizing the necessity of giving more information to the public about the quality of reused wastewater produced by modern treatment methods. Such education would greatly affect the public's perception about wastewater reuse for common purposes.

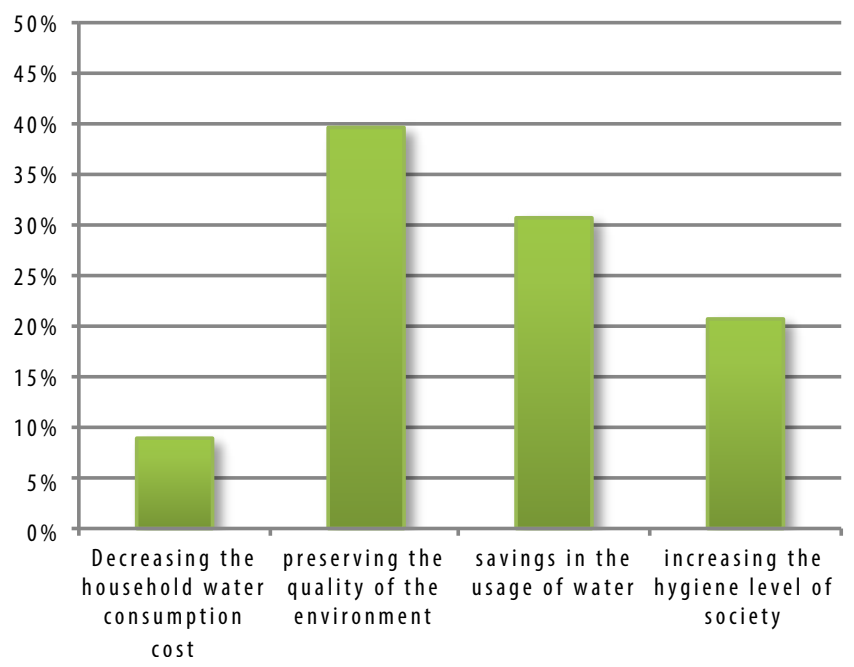

Figure 2 The most important reasons for water reuse based on public judgment.

Since the public's attitudes toward wastewater reuse greatly affect the success of wastewater recycling projects, the sample selected to administer the questionnaire to was a cross section of residents in Tehran, with the characteristics given in Table 2. A summary of the results of the survey is given in Figures 3 through 7 below.

The first four groups of uses represent the highest level of user contact with the water. As expected, the level of contact with the recycled water has an inverse relation with an individual's willingness to use it, meaning that decreasing the level of contact increases the willingness of individuals to use recycled wastewater.

The effect of individual knowledge of wastewater reuse on the acceptance of such reuse is given in Figure 3. The results show that increasing a person's knowledge of the wastewater recycling process increases their level of satisfaction with recycled water use. In most cases, the comments of people with knowledge of recycled water are more precise than those of people who are less familiar with the topic. In cases like irrigating vegetables, people have less knowledge of possible threats, so experts have different judgments about these issues. These observtions imply that increasing public knowledge and the amount of available information of the use of recycled water will greatly influence social acceptance and increase public participation in this issue. 


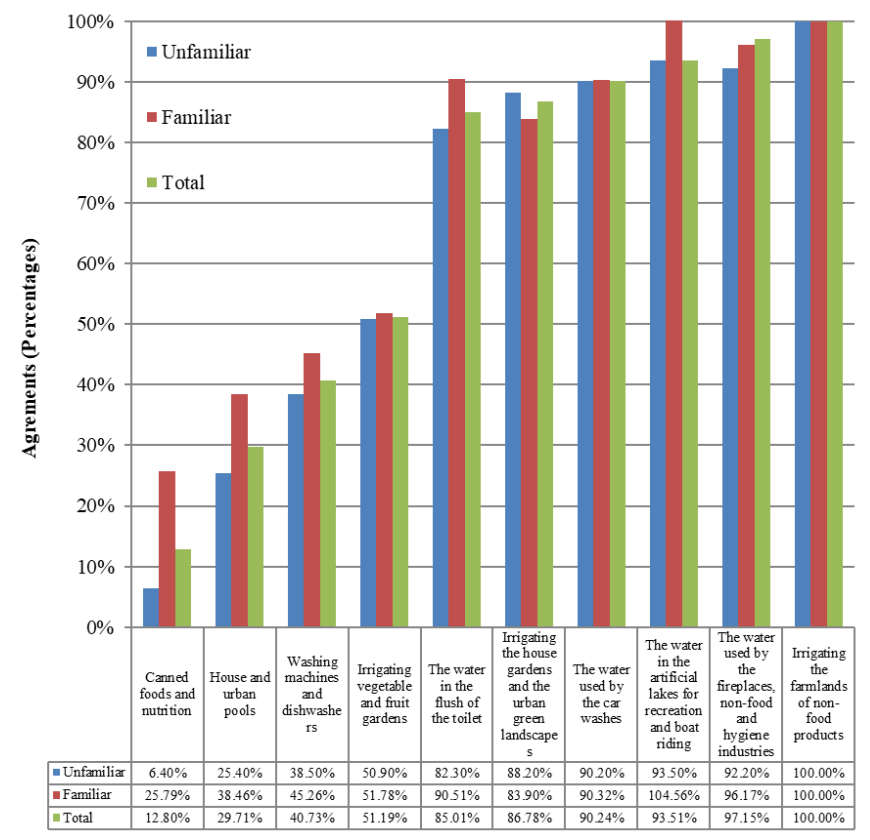

Figure 3 Effect of user knowledge on the acceptance of wastewater reuse.

One important issue is the effect of user gender on the acceptance of recycled water usage. As can be seen in Figure 4, male acceptance of using recycled water is much greater than female, and this difference is intensified by an increase in the level of contact. In educating people about this issue, the gender of the audience should be considered and if possible this education should be done in a way that targets female audiences.

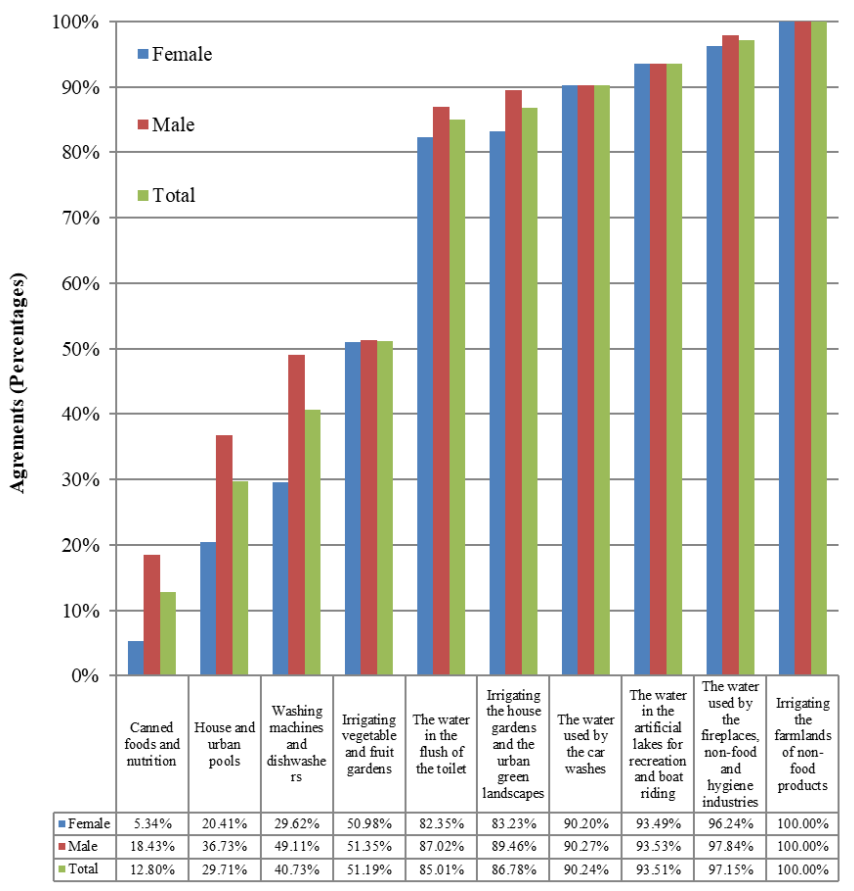

Figure 4 Effect of user gender on the acceptance of wastewater reuse.
The effect of user age on wastewater reuse acceptance is shown in Figure 5. It can be inferred that the acceptance rate of using recycled wastewater by people in the age range 18-30 is much higher than for those in other age ranges. As age increases, the willingness to use recycled water generally decreases. In people under the age of 18, a decrease in acceptance is observed, but since these groups are influenced by their families, this decrease in acceptance is probably changeable. However, since this group consists of the people who will eventually use recycled water, it would be very useful to improve their general knowledge about the necessity and benefits of wastewater reuse. They should also be educated on how to deal with this issue in the future. Furthermore, special attention should be paid to people over the age of 30 to make them familiar with how wastewater reuse benefits their society.

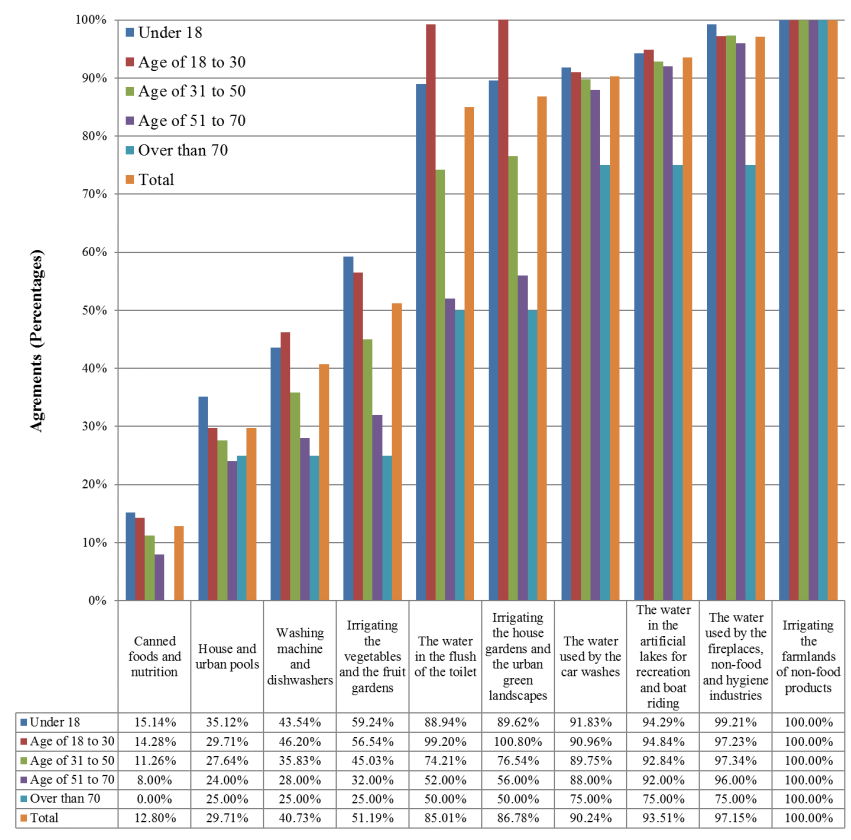

Figure 5 Effect of user age on the acceptance of wastewater reuse.

The other factor that affects user acceptance of wastewater reuse is education level, as shown in Figure 6 . According to Figure 6 , the highest acceptance level is found in the university-educated population, so it is understandable that to increase the acceptance of the usage of recycled water in Tehran, education about this issue should target sections of society with little or no tertiary education.

In addition to the previously-mentioned issues, a person's income level and economic situation have a great impact on their acceptance of wastewater reuse. The effects of user income on wastewater reuse acceptance are given in Figure 7. According to Figure 7, when household income increases, acceptance of the usage of recycled water decreases. Because the lowest acceptance of wastewater reuse is associated with the wealthy segment of society, and considering that this part of society includes a relatively small fraction of the people with enough financial resources 
to provide themselves with different sources of water, it would not be logical to invest in their education because of the low impact on social acceptance as a whole.

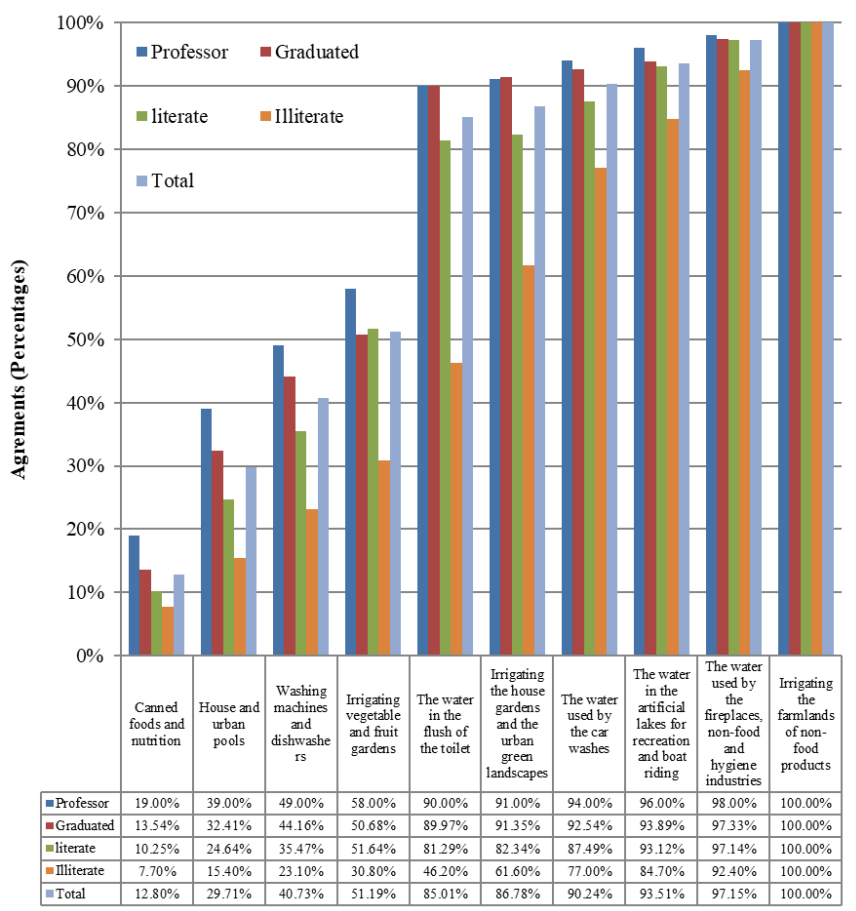

Figure 6 Effect of user education level on the acceptance of wastewater reuse.

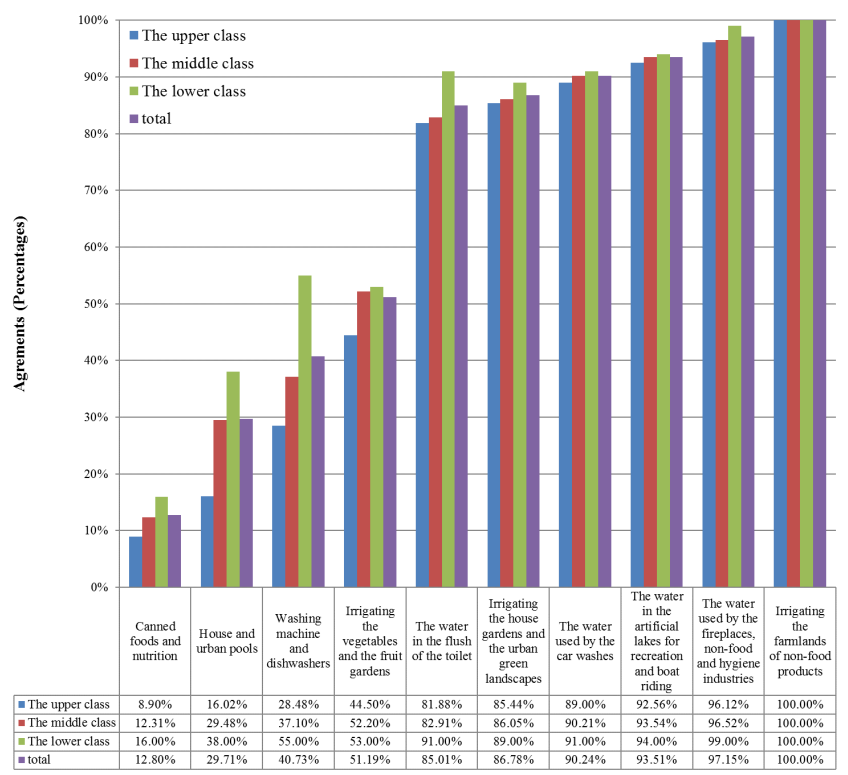

Figure 7 Effect of user income on the acceptance of wastewater reuse.

\section{Conclusions}

In spite of the importance of recycling water, especially urban wastewater that can be used to satisfy a remarkable propor- tion of water demand in urban areas, acceptance of the use of recycled effluent should be studied before any operational plan for water reuse can be developed. In this study, the issue was addressed by preparing and distributing surveys among experts and non-experts and analyzing the results using SWOT. Analysis of the results, with regard to the system and the necessity to take up a defensive policy, determined four strategies that can be advanced:

1. Public education in ways of using the recycled wastewater;

2. Informing the public about the quality of recycled wastewater and the availability of technology and capability of the authorities to provide recycled wastewater of acceptable quality;

3. Public information about the advantages of using recycled wastewater when facing a potentially disastrous water shortage; and

4. Selling water at its real price and informing the public about the high cost of providing water and the necessity to conserve it.

According to the polls, voters state that the most important reason for recycling urban wastewater is preserving the quality of the environment (39.54\%), while decreasing the family economic burden has the least importance (9.09\%). If a method involving increased price is combined with emphasizing the importance of the issue of recycled wastewater, societal acceptance will certainly increase.

The degree of contact with refined wastewater has an inverse relationship with user acceptance; i.e. decreasing the contact level results in an increase in the number of positive comments. The least amount of support for using refined wastewater is related to canned foods and nutrition as a high contact application issue, and the highest level of support is related to irrigating farmlands and ranges, the products of which are not directly used in society, such as cotton farmlands.

With respect to societal comments, it can be understood that an increase in the amount of education and in being informed about the issue would have the greatest effect on the acceptance of using refined wastewater. It would also be better to focus these efforts and education on women $>30 \mathrm{y}$ old, and also to focus on the sections of the city with higher than average levels of income. For other parts of society, various types of strategies which may reach these specific groups of people could have the most impact on increasing the overall level of acceptance of using refined wastewater.

\section{References}

Angelakis, A. N. and P. Gikas. 2014. "Water Reuse: Overview of Current Practices and Trends in the World with Emphasis on EU States." Water Utility Journal 8 (67): e78.

Ardalan, A., M. Khaleghy Rad and M. Hadi. 2019. “Urban Water Issues in the Megacity of Tehran." In Urban Drought. Disaster 
Risk Reduction (Methods, Approaches and Practices), edited by B. Ray and R. Shaw, 263-88. Singapore: Springer.

Baumann, Duane D. and Roger E. Kasperson. 1974. “Public Acceptance of Renovated Waste Water: Myth and Reality." Water Resources Research 10 (4): 667-74.

Bixio, Davide, C. Thoeye, J. De Koning, D. Joksimovic, D. Savic, T. Wintgens and T. Melin. 2006. "Wastewater Reuse in Europe." Desalination 187 (1-3): 89-101.

Bruvold, W. 1972. Public Attitudes Towards Reuse of Reclaimed Water. Berkeley, CA: University of California, Berkeley. Water Resources Center (Contribution No. 137).

Bruvold, William H. and Paul C. Ward. 1972. “Using Reclaimed Wastewater: Public Opinion." Journal of the Water Pollution Control Federation 16 (9): 1690-6.

Bruvold, William H., Betty H. Olson and Martin Rigby. 1981. "Public Policy for the Use of Reclaimed Water." Environmental Management 5 (2): 95-107.

Chen, Weiping, Yanying Bai, Weiling Zhang, Sidan Lyu and Wentao Jiao. 2015. "Perceptions of Different Stakeholders on Reclaimed Water Reuse: The Case of Beijing, China." Sustainability 7 (7): 9696-710.

Coomes, Paul A., Barry D. Kornstein, Thomas D. Rockaway andJoshua A. Rivard. 2010. "North America Residential Water Usage Trends." Proceedings of the Water Environment Federation 2010 (9): 6488-500.

Crook, J. 2003. "An Overview of Water Reuse." International Seminar on Wastewater Reclamation and Reuse.

Daghighi, Amin. 2017. Harmful Algae Bloom Prediction Model for Western Lake Erie Using Stepwise Multiple Regression and Genetic Programming. Cleveland, $\mathrm{OH}$ : Cleveland State University. Master's thesis.

https://engagedscholarship.csuohio.edu/etdarchive/964/

Dishman, C. Michael, Joseph H. Sherrard and Menahem Rebhun. 1989. "Gaining Support for Direct Potable Water Reuse." Journal of Professional Issues in Engineering 115 (2): 154-61.

Dolnicar, Sara and Anna Hurlimann. 2010. “Desalinated versus Recycled Water: What Does the Public Think?" Sustainability Science and Engineering 2:375-88.

Friedler, E. 2008. “The Water Saving Potential and the Socio-Economic Feasibility of Greywater Reuse Within the Urban Sector-Israel as a Case Study." International Journal of Environmental Studies 65 (1): 57-69.

Friedler, Eran, O. Lahav, H. Jizhaki and T. Lahav. 2006. "Study of Urban Population Attitudes Towards Various Wastewater Reuse Options: Israel as a Case Study." Journal of Environmental Management 81 (4): 360-70.

Gheytaspour, Moein and Omid Habibzadeh-Bigdarvish. 2018. "Forecasting Oxygen Demand in Treatment Plant Using Artificial Neural Networks." International Journal of Advanced Engineering Research and Science 5(3).
Habibzadeh-Bigdarvish, Omid, Xinbao Yu, Gang Lei, Teng Li and Anand J. Puppala. 2019. “Life-Cycle Cost-Benefit Analysis of Bridge Deck De-lcing Using Geothermal Heat Pump System: A Case Study of North Texas." Sustainable Cities and Society 47: 101492.

Haghiri, Sadaf, Amin Daghighi and Sina Moharramzadeh. 2018. "Optimum Coagulant Forecasting by Modeling Jar Test Experiments Using ANNs." Drinking Water Engineering and Science 11 (1): 1-8.

Hartley, Troy W. 2006. "Public Perception and Participation in Water Reuse." Desalination 187 (1-3): 115-26.

Hill, Terry and Roy Westbrook. 1997. "SWOT Analysis: It's Time for a Product Recall." Long Range Planning 30 (1): 46-52.

Homaei, Mohammad Hossein, Faezeh Soleimani, Shahaboddin Shamshirband, Amir Mosavi, Narjes Nabipour and Annamaria R. Varkonyi-Koczy. 2020. “An Enhanced Distributed Congestion Control Method for Classical 6LowPAN Protocols Using Fuzzy Decision System." IEEE Access. doi: 10.1109/ACCESS.2020.2968524

Honeycutt, Brandi Leigh. 2015. Public Opinion of Potable Water Reuse in Denver, Colorado. Denver, CO: University of Colorado at Denver. Master's thesis.

Hurlimann, Anna. 2007. “Recycling Water for Australia's Future: The Case of Two Victorian Cities." State of Australian Cities Conference.

Ketabchy, Mehdi. 2018. Thermal Evaluation of an Urbanized Watershed using SWMM and MINUHET: A Case Study of Stroubles Creek Watershed, Blacksburg, VA. Blacksburg, VA: Virginia Tech. Master's thesis.

McGovern, C. and R. Bastian. 2009. Water Recycling and Reuse: The Environmental Benefits. Washington, DC: United States Environmental Protection Agency.

McKenzie, Caigan. 2004. "Wastewater Reuse Conserves Water and Protects Waterways." Small Flows Quarterly 5(3).

Miller, Evonne, Lorraine M. Bell and Laurie Buys. 2007. “Public Understanding of Carbon Sequestration in Australia: Socio-Demographic Predictors of Knowledge, Engagement and Trust." International Journal of Emerging Technologies and Society 5 (1): 15-33.

Nahvi, Ali, Amin Daghighi and Sara Nazif. 2018. "The Environmental Impact Assessment of Drainage Systems: A Case Study of the Karun River Sugarcane Development Project." Archives of Agronomy and Soil Science 64 (2): 185-95.

Po, Murni, Blair E. Nancarrow and Juliane D. Kaercher. 2003. Literature Review of Factors Influencing Public Perceptions of Water Reuse. Perth, Australia: Commonwealth Scientific and Industrial Research Organisation (CSIRO). Technical Report $54 / 03$.

Po, Murni, Blair E. Nancarrow, Zoe Leviston, Natasha B. Porter, Geoffrey J. Syme and Juliane D. Kaercher. 2005. Predicting Community Behaviour in Relation to Wastewater Reuse: What Drives Decisions to Accept or Reject? Perth, Australia: 
Commonwealth Scientific and Industrial Research Organisation (CSIRO).

Population and Household Census city in the country based on the General Population and Housing. "عمومى نفوس و مسكن "جمعيت و خانو ار شهرستان هاى كثور بر اساس سرشمارى "Statistical Center of Iran. In Persian.

Queensland Water Commission. 2007. Final Report, May 2007 (online), Available: http://www.qwc.qld.gov.au/myfiles/ uploads/institutional\%20arrangements/Urban_Water_Supply_Arrangements_in_SEQ.pdf (23 February 2009).

Roman, Alicia, Martina Winker, Felix Tettenborn and Ralf Otterpohl. 2007. "Informal Settlements and Wastewater Reuse: Improve of Urban Environment and Alleviate Poverty in Lima, Peru." 2nd SWITCH Scientific Meeting, Dan Panorama Hotel, Tel-Aviv, Israel 25-29 November, 2007.

Scott, Christopher Anand, J. Antonio Zarazúa and Gilbert Levine. 2000. Urban-Wastewater Reuse For Crop Production in the Water-Short Guanajuato River Basin, Mexico. Colombo, Sri Lanka: International Water Management Institute (IWMI).

Sims, John H. and Duane D. Baumann. 1974. “Renovated Waste Water: The Question of Public Acceptance." Water Resources Research 10 (4): 659-65.
Statistical Center of Iran. 2013. The Results of the Survey of Income and Expenditure of Urban Households."Tehran: Statistical Centre of Iran.

https://www.amar.org.ir/english/Metadata/Statistical-Survey/Household-Expenditure-and-Income

Tabesh, M. and M. Dini. 2009. "Fuzzy and Neuro-Fuzzy Models for Short-Term Water Demand Forecasting in Tehran." Iranian Journal of Science and Technology 33 (B1): 61.

Wirth, Nikolaus. 2010. Wastewater Re-use in Lima Metropolitana: A Concept for an Integrated and Sustainable Water and Wastewater Management. Emden: University of Applied Sciences (Hochschule Emden-Leer). Master's thesis.

World Health Organization. 2006. Guidelines for the Safe Use of Wastewater, Excreta and Greywater, Vol. 1. World Health Organization.

Wu, Laosheng et al. 2009. Safe Application of Reclaimed Water Reuse in the SouthWestern United States. Vol. 8357. UCANR Publications. 